I N S T I T U T O

DE

M E D I C I N A

T R O P I C A L

$\mathrm{DE}$

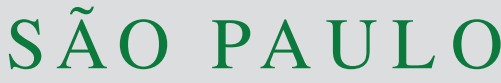

JOURNAL OF THE SÃO PAULO INSTITUTE OF TROPICAL MEDICINE

${ }^{1}$ Instituto de Infectologia Emílio Ribas, São Paulo, São Paulo, Brazil

Universidade de São Paulo, Hospital das Clínicas, Departamento de Doenças Infecciosas, São Paulo, São Paulo, Brazil

${ }^{3}$ Universidade de São Paulo, Hospital das Clínicas, Departamento de Radiologia, São Paulo, São Paulo, Brazil

${ }^{4}$ Universidade de São Paulo, Hospital das Clínicas, Departamento de Neurologia, São Paulo, São Paulo, Brazil

Correspondence to: Flávia Esper Dahy Instituto de Infectologia Emílio Ribas, Av. Dr. Arnaldo, 165, CEP 01246-900, São Paulo, SP, Brazil,

Tel: +55 11 3896-1200

E-mail: neuro.flaviaesper@gmail.com

Received: 8 December 2020

Accepted: 26 February 2021

\section{Sporadic Creutzfeldt-Jakob disease in two clinically and virologically controlled Brazilian HIV patients who progressed rapidly to dementia: case reports and literature review}

Flávia Esper Dahy ${ }^{\circledR 1}$, Christina T. G. Novaes ${ }^{\circledR 2}$, Gabriela A. Bandeira ${ }^{\circledR}$, Laís F. Ramin ${ }^{\circledR 3}$, Augusto César Penalva de Oliveira ${ }^{\circledR 1}$, Jerusa Smid ${ }^{\circledR 1,4}$

\section{ABSTRACT}

Human immunodeficiency virus (HIV)-associated neurocognitive disorders are the main cause of cognitive decline and dementia in people living with HIV (PLHIV). However, extensive workup should be done in patients with rapidly progressive dementia (RPD) and HIV, especially when secondary infection in the central nervous system (CNS) is ruled out. Sporadic Creutzfeldt-Jakob disease (sCJD) is the main cause of RPD in non-HIV patients. It is a fatal neurodegenerative condition caused by prions that mainly affects elderly patients. Our objective is to describe two cases of PLHIV presenting with controlled infections and SCJD, and to review the literature. Our patients were younger than expected for SCJD and one of them had a longer disease course. As aging is expected to occur earlier in PLHIV, sCJD must be excluded in younger PLHIV presenting with RPD and without CNS infection.

KEYWORDS: HIV. Dementia. Prion disease. Creutzfeldt-Jakob disease. HAND.

\section{INTRODUCTION}

The most prevalent cognitive disorders in people living with human immunodeficiency virus - HIV (PLHIV) are HIV-associated neurocognitive disorders (HAND). However, rapidly progressive dementia (RPD) in this population should be investigated in the same way as in seronegative individuals.

The leading cause of RPD are prion diseases (PD), mostly sporadic CreutzfeldtJakob disease (sCJD). PD are neurodegenerative disorders caused by the conversion of a normal cellular prion protein (PrPC) into its abnormal and pathogenic form called prion. The median age at onset of symptoms is 67 years, ranging from 55 to 75 years, with a median survival of five months ${ }^{1}$.

We describe the rare association of two clinical conditions: SCJD and HIV infection in two patients with clinically-controlled HIV, undetectable viral load and no history of opportunistic CNS infection. In addition, we reviewed the literature and compared our cases to previously published ones that are only five, to date $e^{2-6}$.

\section{CASE REPORT}

Patient 1 was a 52 years old man whose HIV infection was diagnosed in 2000, presenting with a controlled disease since then, without opportunistic CNS infections. In June 2018, he had an insidious behavior change, insomnia and difficulties at work. His neurological examination revealed a global cerebellar syndrome, bilateral Babinski, 4-limb paratonia and release of face axial reflexes. 
The cognitive evaluation showed memory, attention and executive function deficits.

The electroencephalogram (EEG) was normal; the cerebrospinal fluid (CSF) analysis revealed an undetectable HIV viral load and normal protein level and positive14.3.3 protein. The brain magnetic resonance imaging (MRI) showed bilateral hyper intensity of images in caudal nuclei during the fluid acquisition inversion recovery (FLAIR) and diffusion-weighted imaging (DWI) sequences; the prion protein gene (PRNP) analysis excluded the presence of mutations and codon 129 was heterozygous (M129V). He died in July 2019, 13 months after the initial symptoms.

Patient 2, a 61 years old man, diagnosed with HIV infection in 1997, presenting with a controlled disease since then, without any opportunistic infection. In February 2019, he reported asthenia, lack of appetite, difficulty sleeping and occasional memory lapses. Two months later, he evolved with uncoordinated steps and the need of support to walk, in addition to visual delusions and bladder incontinence.

His neurological examination revealed four limbs paratonia and a global cerebellar syndrome, aside from lower limbs hyporeflexia. The cognitive evaluation showed dementia associated with a dysexecutive syndrome and also episodic memory and attention deficits.

His MRI showed bilateral asymmetric cortical ribboning in the cerebral cortex at DWI and FLAIR. Bilateral thalami and striatum hyper intense images, with an anterior to posterior gradient were also observed at DWI (Figure 1) and FLAIR (Figure 2). The CSF analysis revealed elevated protein $(85 \mathrm{mg} / \mathrm{dL})$, undetectable HIV viral load, elevated Tau protein $(2,520 \mathrm{pg} / \mathrm{mL})$, positive 14.3 .3 protein and

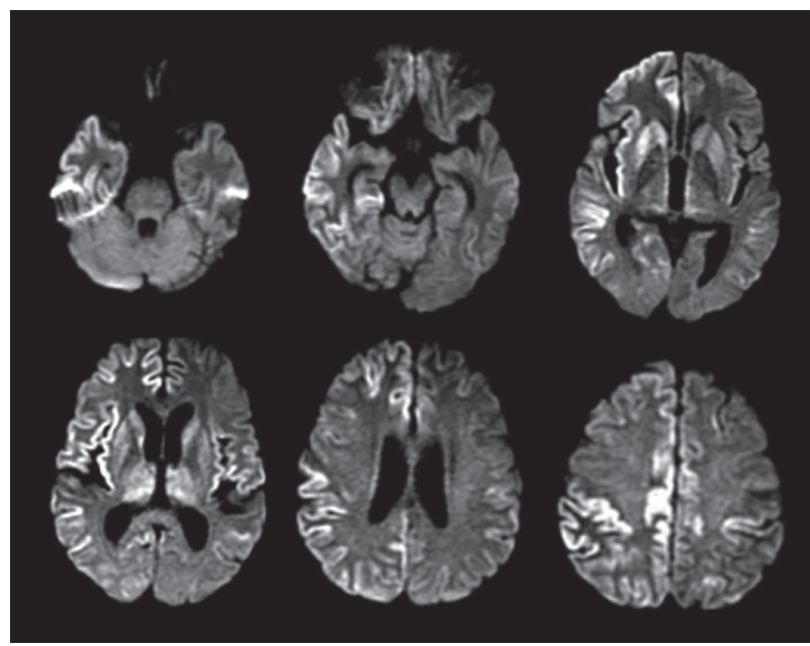

Figure 1 - Diffusion-weighted imaging (DWI) - bilateral restricted diffusion cortical ribboning is shown in frontal, temporal and parietal cortices, also in the insula, most evident on the right. Similar alteration of the signal affects the thalamus, lentiform nuclei and caudate nucleus, mainly on the right.

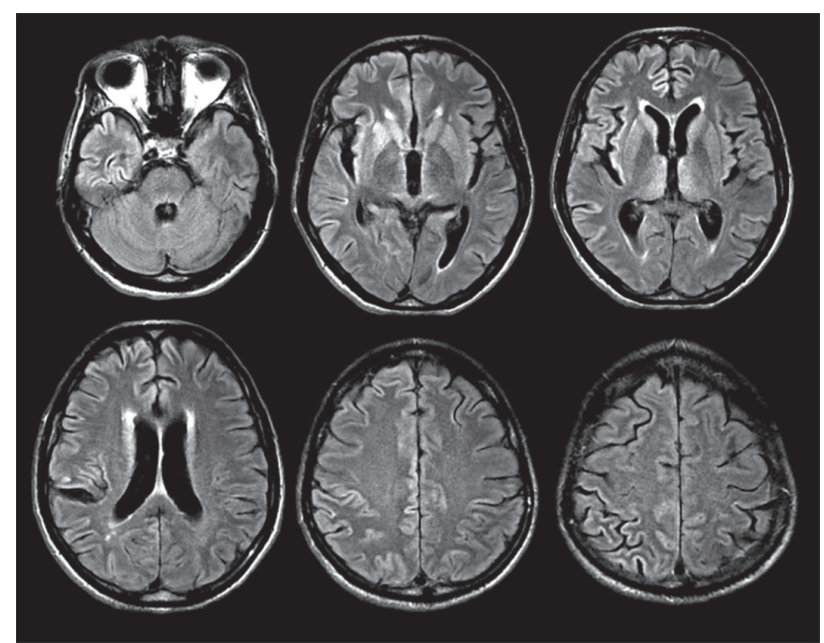

Figure 2 - Fluid acquisition inversion recovery (FLAIR) sequences - asymmetric hyperintensities in the cerebral cortex, most evident on the right. Alterations are also seen in nuclei of the base and thalamus, bilaterally. Note that hyper intensities are brighter in DWI acquisition than in FLAIR sequence.

detection of prion by real-time quaking induced conversion (RT-QuIC). He died five months after the initial symptoms.

\section{DISCUSSION}

In the face of RPD in PLHIV, classical causes of cognitive impairment in this population should be ruled out, but it is extremely important to consider other diagnoses that are not directly linked to HIV.

Creutzfeldt-Jakob disease (CJD) is a rare, fatal and neurodegenerative disease classically characterized by rapidly progressive dementia and ataxia, extrapyramidal or pyramidal symptoms and myoclonus. The disease may occur in sporadic, genetic and acquired forms ${ }^{7}$. Sporadic forms account for $85 \%$ of CJD cases. The neurological impairment (extrapyramidal, pyramidal, cerebellar, visual disturbances), myoclonus and akinetic mutism are part of clinical diagnostic criteria $^{8-11}$. The causative agent is called prion (or scrapie prion protein, PrPsc), a pathogenic form of the normal cellular prion protein $(\mathrm{PrPc})$. The conversion of PrPc to PrPsc leads to neurodegeneration and neuronal death ${ }^{6}$.

According to the World Health Organization - WHO (1998), possible sCJD are those with progressive dementia, symptoms that progress in less than two years, with at least two out of the four clinical features: 1) myoclonus, 2) visual or cerebellar disturbance, 3) pyramidal/extrapyramidal dysfunction, and 4) akinetic mutism; probable SCJD are those possible CJD clinical criteria and subsidiary positive tests (typical EEG or 14.3.3 protein in CSF analysis) ${ }^{8}$.

The University of California criteria (2007) define probable cases of sCJD as those with rapid cognitive decline associated with at least two specific neurological 
manifestations: myoclonus, pyramidal or extrapyramidal, visual, cerebellar, akinetic mutism or other focal higher cortical sign and at least one of ancillary tests: typical EEG or positive MRI; routine investigations that do not suggest an alternative diagnosis ${ }^{9}$.

According to the European criteria (2017), sCJD probable cases are classified in the presence of a rapidly progressive cognitive impairment and two of the characteristic neurological impairment signs, in addition to symptoms from WHO criteria associated with either typical EEG, or typical MRI change or CSF protein 14.3.3 positivity, or any progressive neurological syndrome associated with positive RT-QuIC ${ }^{10}$.

Restriction of diffusion in the basal ganglia and/or more than one cortical region, absence of contrast enhancement, and absence of white matter involvement strongly suggest the diagnosis of CJD in a patient with an appropriate clinical context $^{12}$

The typical EEG shows generalized periodic discharges. Diffuse disruption of the brain electrical activity or periodic lateralized discharges are observed in some cases ${ }^{3}$.

The presence of the 14.3.3 protein and high levels of total tau protein in the CSF analysis supports the diagnosis

The histopathological analysis shows neuronal loss, gliosis and spongiform vacuolization in the absence of inflammatory response ${ }^{12}$. In all criteria, defined CJD requires the presence of prion within the CNS tissue, confirmed either by immunohistochemical or by biochemical techniques.

More recently, a technique for identifying prion in vivo called RT-QuIC has been developed. In a recent study of the National Prion Disease Pathology Surveillance Center of the United States of America ${ }^{13}$ that analyzed 10,498 CSF specimens, the sensitivity was $90.3 \%$ and specificity $98.5 \%$ for CJD diagnosis by a second-generation RT-QuIC. This technique became a useful tool for the in vivo diagnosis of CJD.

Nowadays, because of the wide distribution of antiretroviral therapy to PLHIV worldwide and successful immune reconstitution among this population, significantly lower incidences of opportunistic infections and mortality rates are observed. Currently, HIV treatment promotes longer survival rates, closing the life expectancy gap between infected and uninfected individuals ${ }^{14-16}$.

The life expectancy and consequently aging have increased in prevalence in HIV among the elderly ${ }^{17}$ and a simultaneous increase in the number of HIV patients suffering from chronic diseases typical of this age group ${ }^{18}$, such as diabetes, cardiovascular and neurodegenerative disorders has appeared

The way HIV, as well as antiretroviral drugs, have influenced chronic diseases of the elderly, particularly neurological ones need to be better understood. Potentially, these patients are under higher risk of vascular events ${ }^{19}$ and a reduction in the subcortical and cortical volume is observed with aging, and there seems to be a greater reduction of the cortical volume in older PLHIV, in comparison with HIV-negative individuals of the same age ${ }^{20}$.

Considering the seven cases of SCJD in PLHIV, five of the literature, in addition to those reported in this article, six of them were below the mean and median age of onset of symptoms reported to non-HIV patients, which is 64 and 67 years old, respectively. Two patients had longer survival than expected in the general population with prion disease and all the patients with long-term HIV infections were well controlled. Only one patient had the onset of RPD symptoms a few months after the diagnosis of HIV infection ${ }^{6}$. Table 1 summarizes the comparison of cases of SCJD in PLHIV.

We consider that HIV and CJD are non-communicable diseases and the younger age of onset of CJD in PLHIV is

Table 1 - Comparison of seven cases of sporadic Creutzfeldt-Jakob disease, in people living with the human immunodeficiency virus (HIV).

\begin{tabular}{|c|c|c|c|c|c|}
\hline Case & Age (years) & $\begin{array}{c}\text { Time of HIV infection } \\
\text { (months) }\end{array}$ & $\begin{array}{l}\text { Evolution time to } \\
\text { death (months) }\end{array}$ & Diagnostic criteria & Reference \\
\hline 1 & 66 & 240 & 3 & Definite case & Babi et al. ${ }^{2}$ \\
\hline 2 & 59 & 3 & 2 & Definite case & Eimer et al. ${ }^{3}$ \\
\hline 3 & 62 & 360 & 4 & Definite case & Abu-Rumeileh et al. ${ }^{4}$ \\
\hline 4 & 63 & 36 & 10 & Definite case & van de Ven et al. ${ }^{5}$ \\
\hline 5 & 52 & Not available & $\begin{array}{c}2 \text { months after } \\
\text { hospitalization. } \\
\text { Total illness time not } \\
\text { available }\end{array}$ & Probable sCJD & Carvalho Neto et al. ${ }^{6}$ \\
\hline 6 & 52 & 228 & 13 & Probable sCJD & This study \\
\hline 7 & 61 & 288 & 5 & Probable sCJD & This study \\
\hline
\end{tabular}

HIV = human immunodeficiency virus; sCJD = sporadic Creutzfeldt-Jakob disease. 
associated with a higher vulnerability of these elder patients to neurodegenerative diseases, but this case report is insufficient to rule out a causative association between both diseases.

\section{CONCLUSION}

Living with HIV has become a chronic medical condition with a longer life expectancy. PLHIV nowadays are more susceptible to neurodegenerative conditions associated with aging, and few cases of SCJD in PLHIV patients have been described so far. The association between these conditions remains unclear. It is important that physicians, especially infectious disease specialists and neurologists, be aware of the multiple etiologies of RPD, including SCJD in this particular population.

\section{ACKNOWLEDGMENTS}

We thank our patients and their families for trusting us during the follow-up and the preparation of this cases report.

\section{AUTHORS' CONTRIBUTIONS}

FED: concept, first draft and discussion; CTGN: concept, discussion and manuscript revision; GAB: discussion; LFR: discussion; ACPO: manuscript revision; JS: concept, manuscript revision and final version.

\section{REFERENCES}

1. Geschwind MD. Prion diseases. Continuum (Minneap Minn). 2015;21:1612-38.

2. Babi MA, Kraft BD, Sengupta S, Peterson H, Orgel R, Wegermann $\mathrm{Z}$, et al. Related or not? Development of spontaneous Creutzfeldt-Jakob disease in a patient with chronic, wellcontrolled HIV: a case report and review of the literature. SAGE Open Med Case Rep. 2016;4: 2050313 X16672153.

3. Eimer J, Vesterbacka J, Savitcheva I, Press R, Roshanisefat $\mathrm{H}$, Nowak P. Nonopportunistic infection leading to rapidly progressive dementia in a patient with HIV/AIDS: a case report. Medicine (Baltimore). 2018;97:e0162.

4. Abu-Rumeileh S, Baiardi S, D’Angelo R, Dentale N, Fasulo $\mathrm{G}$, Guarino $\mathrm{M}$, et al. Clinical reasoning: rapidly progressive dementia in a patient with HIV after an exotic journey. Neurology. 2018;91:e1360-4.

5. van de Ven NS, Vera J, Jones JR, Vundavalli S, Ridha BH. Sporadic CJD in association with HIV. J Neurol. 2018;266:253-7.

6. Carvalho Neto EG, Gomes MF, Oliveira M, Guete MI, Santos IP, Monteiro MD, et al. The worst is yet to come: probable sporadic Creutzfeldt-Jakob disease in a well-controlled HIV patient. Prion. 2019;13:156-9.
7. Zerr I, Parchi P. Sporadic Creutzfeldt-Jakob disease. Handb Clin Neurol. 2018;153:155-74.

8. World Health Organization. Global surveillance, diagnosis and therapy of human transmissible spongiform encephalopathies: report of a WHO consultation: Geneva, Switzerland, 9-11 February 1998. Geneva: WHO; 1998. [cited 2021 Feb 26]. Available from: https://www.who.int/csr/resources/ publications/bse/WHO_EMC_ZDI_98_9/en/

9. Geschwind MD, Josephs KA, Parisi JE, Keegan M. A 54-year-old man with slowness of movement and confusion. Neurology. 2007;69:1881-7.

10. National Creutzfeldt-Jakob Disease Research \& Surveillance Unit. University of Edinburgh. Protocol: surveillance of CJD in the UK. [cited $2021 \mathrm{Feb} 26$ ]. Available from: https://www. cjd.ed.ac.uk/sites/default/files/NCJDRSU\%20surveillance $\% 20$ protocol-april\%202017\%20rev2.pdf

11. Prusiner SB. Shattuck lecture: neurodegenerative diseases and prions. N Engl J Med. 2001;344:1516-26.

12. Rudge P, Hyare H, Green A, Collinge J, Mead S. Imaging and CSF analyses effectively distinguish CJD from its mimics. J Neurol Neurosurg Psychiatry. 2018;89:461-6.

13. Rhoads DD, Wrona A, Foutz A, Blevins J, Glisic K, Person M, et al. Diagnosis of Prion diseases by RT-QuIC results in improved surveillance. Neurology. 2020;95:e1017-26

14. Marcus JL, Chao CR, Leyden WA, Xu L, Quesenberry CP Jr, Klein DB, et al. Narrowing the gap in life expectancy between HIV-infected and HIV-uninfected individuals with access to care. J Acquir Immune Defic Syndr. 2016;73:39-46.

15. May MT, Gompels M, Delpech V, Porter K, Orkin C, Kegg S, et al. Impact on life expectancy of HIV-1 positive individuals of CD4R cell count and viral load response to antiretroviral therapy. AIDS. 2014;28:1193-202.

16. Teeraananchai S, Kerr SJ, Amin J, Ruxrungtham K, Law MG. Life expectancy of HIV-positive people after starting combination antiretroviral therapy: a meta-analysis. HIV Med. 2017;18:25666.

17. Mills EJ, Bärnighausen T, Negin J. HIV and aging: preparing for the challenges ahead. N Engl J Med. 2012;366:1270-73.

18. Hasse B, Ledergerber B, Furrer H, Battegay M, Hirschel B, Cavassini M, et al. Morbidity and aging in HIV-infected persons: the Swiss HIV cohort study. Clin Infect Dis. 2011;53:1130-9.

19. Durand M, Chartrand-Lefebvre C, Baril JG, Trottier S, Trottier B, Harris M, et al. The Canadian HIV and aging cohort study: determinants of increased risk of cardiovascular diseases in HIV-infected individuals: rationale and study protocol. BMC Infect Dis. 2017;17:611.

20. Guha A, Brier MR, Ortega M, Westerhaus E, Nelson B, Ances $\mathrm{BM}$. Topographies of cortical and subcortical volume loss in HIV and aging in the cART era. J Acquir Immune Defic Syndr, 2016;73:374-83. 